\title{
Role of Leukotriene Receptor Antagonists in the Treatment of Exercise-Induced Bronchoconstriction: A Review
}

George S. Philteos, MD, FRCP(C); Beth E. Davis, BSc; Donald W. Cockcroft, MD, $\operatorname{FRCP}(\mathrm{C})$; Darcy D. Marciniuk, MD, $\operatorname{FRCP}(\mathrm{C})$

\begin{abstract}
Asthma is a very common disorder that still causes significant morbidity and mortality. A high percentage of individuals with asthma also experience exercise-induced bronchoconstriction (EIB). This article reviews the current literature and updates the reader on the safety, efficacy, and clinical applications of leukotriene modifiers in the treatment of EIB.
\end{abstract}

Asthma affects 14 to 15 million people in the United States and is responsible for more than 100 million days of restricted activity, more than 5,000 deaths, and 470,000 hospitalizations each year. ${ }^{1}$ Previously characterized as a disease of airway smooth muscle, asthma is currently defined by the National Heart, Lung, and Blood Institute as "a chronic inflammatory disorder of the airways in which many cells and cellular elements play a role, in particular, mast cells, eosinophils, T lymphocytes, macrophages, neutrophils, and epithelial cells." ${ }^{2}$ Exercise-induced bronchoconstriction (EIB) occurs in approximately 80 to $90 \%$ of individuals with asthma and in approximately $11 \%$ of the general population without otherwise symp-

G. S. Philteos, B. E. Davis, D. W. Cockcroft, D. D. Marciniuk-Division of Respiratory Medicine, Department of Medicine, University of Saskatchewan, Royal University Hospital, Saskatoon, Saskatchewan; D. D. Marciniuk - Lung Association of Saskatchewan COPD Professorship; D. W. Cockcroft-Lung Association of Saskatchewan Ferguson Professorship

Correspondence to: Dr. D. D. Marciniuk, Division of Respiratory Medicine, University of Saskatchewan, Ellis Hall, Rm. 545, 5th Floor, Saskatoon, SK S7N 0W8 tomatic asthma., ${ }^{3,4}$ This article reviews the current literature and updates the reader on the safety, efficacy, and clinical applications of leukotriene modifiers in the treatment of EIB.

\section{Role of Leukotrienes in Asthma Pathogenesis}

Various biologic signals (including receptor activation, antigen-antibody interaction, and physical stimuli such as cold) activate cytosolic phospholipase $\mathrm{A}_{2}$ to liberate arachidonic acid from membrane phospholipids. ${ }^{5}$ The liberated arachidonic acid is then metabolized to various active compounds, including the leukotrienes $\mathrm{LTB}_{4}, \mathrm{LTC}_{4}$, $\mathrm{LTD}_{4}$, and $\mathrm{LTE}_{4}$ (Figure 1).

$\mathrm{LTC}_{4}, \mathrm{LTD}_{4}$, and $\mathrm{LTE}_{4}$, formerly known collectively as slow-reacting substance of anaphylaxis, are collectively called the cysteinyl leukotrienes. The dose of $\mathrm{LTD}_{4}$ required to produce clinical bronchoconstriction has been estimated to be 1,000 - to 10,000 -fold lower than that of histamine or methacholine, which indicates that these mediators are extremely potent. ${ }^{5}$ The cysteinyl leukotrienes exert their biologic effects by binding to cysteinyl leukotriene receptors (specifically 


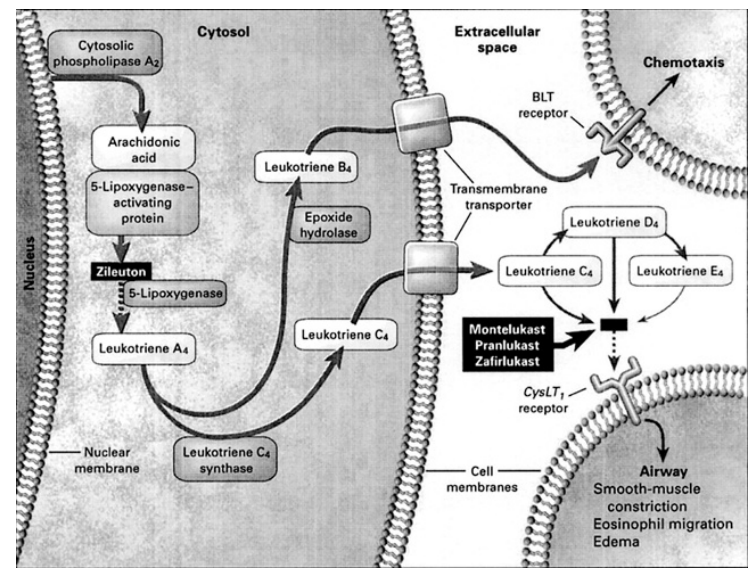

Figure 1 Biosynthesis and physiologic effects of leukotrienes and pharmacologic actions of antileukotrienes. Reproduced with permission from Drazen et al. ${ }^{6} \mathrm{BLT}=\mathrm{B}$ leukotriene receptor.

subtype 1, CysLT 1 ) on airway smooth muscle and bronchial vasculature, and they contribute to the bronchospasm, increased bronchial hyperresponsiveness, mucus production and mucosal edema, enhanced smooth-muscle cell proliferation, and eosinophilia that are characteristic of the asthmatic airway. ${ }^{6}$ Both bronchial and bronchoalveolar lavage studies have provided evidence of increased levels of cysteinyl leukotrienes in the airways of asthmatic individuals. ${ }^{7}$ Mast cells synthesize and release leukotrienes in those who are susceptible to exercise-induced bronchoconstriction (EIB) but are probably not the only source, especially in individuals with underlying airway inflammation. Additionally, because mast cells are known to release more than one bronchoconstricting agent, EIB probably does not result from the action of a single mediator. (An in-depth discussion of the mediators involved in EIB and their cellular sources are beyond the scope of this review.)

\section{Exercise-Induced Bronchoconstriction}

EIB occurs in individuals of all ages but particularly in children and young adults for whom physical activity is common. EIB is bronchoconstriction that develops occasionally during physical activity (if the activity is of sufficient duration) but usually develops 10 to 30 minutes after physical activity in individuals with underlying airway hyperresponsiveness. ${ }^{4}$ The occurrence of EIB in asthmatic persons is common and often signifies suboptimal control of asthma. ${ }^{8}$

The diagnosis of EIB is confirmed in the laboratory by a drop of $15 \%$ or more in forced expiratory volume in 1 second $\left(\mathrm{FEV}_{1}\right)$ after vigorous exercise for 6 minutes, according to American Thoracic Society guidelines. ${ }^{9}$ A postexercise drop of 10 to $15 \%$ in $\mathrm{FEV}_{1}$ would be considered "probable EIB.” Minute ventilation (exercise intensity), temperature and humidity of the inspired air (climatic conditions), and underlying baseline airway responsiveness are the primary determinants of the degree of EIB a patient will experience. ${ }^{4}$ The exact mechanism leading to EIB is not yet fully understood but probably relates to drying and/or cooling of the airway mucosa and to mediator release. ${ }^{3}$ Many studies, however, have demonstrated the protective effect of $\mathrm{CysLT}_{1}$ receptor antagonists against EIB, providing strong evidence of an important role of cysteinyl leukotrienes in regard to EIB. ${ }^{10}$

\section{Treatment of Exercise-Induced Bronchoconstriction}

\section{Nonpharmacologic Measures}

A warm-up period of light exercise lasting at least 10 minutes may lessen the degree of EIB experienced for 40 minutes to 3 hours. ${ }^{11}$ Exercising in a warm humidified environment (if possible) and gradually lowering the intensity of exercise have also been proposed to lessen the degree of EIB experienced by patients. ${ }^{11}$

\section{Pharmacologic Measures}

\section{Short-Acting $\boldsymbol{\beta}_{\mathbf{2}}$ Agonists}

A short-acting $\beta_{2}$ agonist given 15 minutes to 1 hour before exercise can prevent EIB symptoms for up to 4 hours, ${ }^{12}$ but this bronchoprotective effect has been observed to significantly decrease after 1 week of regular use. ${ }^{13}$ 


\section{Long-Acting $\boldsymbol{\beta}_{\mathbf{2}}$ Agonists}

The long-acting $\beta_{2}$ agonists formoterol and salmeterol both will inhibit EIB for up to 12 hours, but formoterol is more rapidly effective. ${ }^{12}$ However, regular use of long-acting inhaled $\beta_{2}$ agonists has resulted in tachyphylaxis, ${ }^{12}$ as evidenced by diminished bronchoprotection by 6 to 9 hours. ${ }^{14}$

\section{Cromones}

Cromolyn and nedocromil inhibit EIB when used prior to exercise. However, they are not as effective as inhaled $\beta_{2}$ agonists are in the management of EIB. ${ }^{12}$

\section{Other Agents}

Anticholinergics, antihistamines, $\alpha$ agonists, and oral $\beta_{2}$ agonists have also been investigated for the treatment of EIB. ${ }^{12}$ Results are varied; routine use of these types of pharmacologic intervention is not recommended as primary treatment of EIB ${ }^{12}$ Other therapies are still being investigated. ${ }^{12}$

\section{Inhaled Corticosteroids}

Regular use of inhaled corticosteroids is effective maintenance therapy and reduces EIB $\cdot{ }^{15}$ An acute protective effect has been observed 4 hours after inhalation in one small study. ${ }^{16}$

\section{Thromboxane Inhibitors}

Thromboxane $\mathrm{A}_{2}$ synthesis inhibitors, especially if combined with leukotriene receptor antagonists, have been shown to protect against EIB. ${ }^{17}$

\section{Leukotriene Modifiers}

\section{Leukotriene Synthesis Inhibitors}

The physiologic effects of leukotrienes are inhibited by drugs known as leukotriene modifiers. The blocking of leukotriene-mediated effects can be achieved by administering receptor antagonists (zafirlukast, montelukast) or by targeting enzymes involved in leukotriene biosynthesis. Zileuton is a 5-lipoxygenase inhibitor that inhibits the formation of $\mathrm{LTA}_{4}$ from arachidonic acid, thereby preventing cysteinyl leukotriene synthesis (see Figure 1). Blocking arachidonic enzymatic conversion by the use of 5-lipoxygenase inhibitors does protect against $\mathrm{EIB}^{18}$ but to a lesser degree and for a shorter duration when compared with the use of receptor antagonists. ${ }^{19}$

\section{Leukotriene Receptor Antagonists}

Leukotriene receptor antagonists (LTRAs) have been shown to decrease airway responsiveness to methacholine, allergens, and cold air. ${ }^{7}$ In aspirinsensitive individuals, LTRAs inhibit the response to acetylsalicylic acid challenge and improve asthma control. ${ }^{7}$ LTRAs may also have a role as corticosteroid-sparing agents. ${ }^{1}$ For asthmatic individuals, zafirlukast provides protection against EIB when administered immediately prior to exercise, ${ }^{4}$ and a single oral dose has been shown to attenuate EIB in children ${ }^{20}$ and in adults. ${ }^{19}$ Montelukast has been the most extensively studied LTRA. Its protective effects against EIB have been seen to occur as early as 1 hour ${ }^{19}$ and up to 24 hours after a single oral dose. ${ }^{14,21}$ When montelukast is administered on a regular basis, protection against EIB is maintained over 12 weeks, without the development of tolerance. ${ }^{22}$

\section{Montelukast Comparison Studies}

Literature that directly compares the use of montelukast with the use of other bronchoprotective anti-inflammatory or bronchodilator agents is accumulating. To date, studies comparing salmeterol with montelukast and studies comparing budesonide with montelukast have been published. Villaran and colleagues ${ }^{23}$ compared $10 \mathrm{mg}$ of oral montelukast administered daily to $50 \mu \mathrm{g}$ of inhaled salmeterol administered twice daily and found no significant difference in protection against EIB after 3 days of treatment. However, after 4 and 8 weeks of regular dosing, montelukast was significantly more effective than salmeterol in attenuating EIB, as evidenced by a greater reduction in $\mathrm{FEV}_{1}$ drop, area under the curve (0-60 minutes), and time to recovery (Figure 2). The difference is attributed to the development of tolerance following regular administration of a long-acting $\beta_{2}$ agonist and the absence of tolerance with regular 

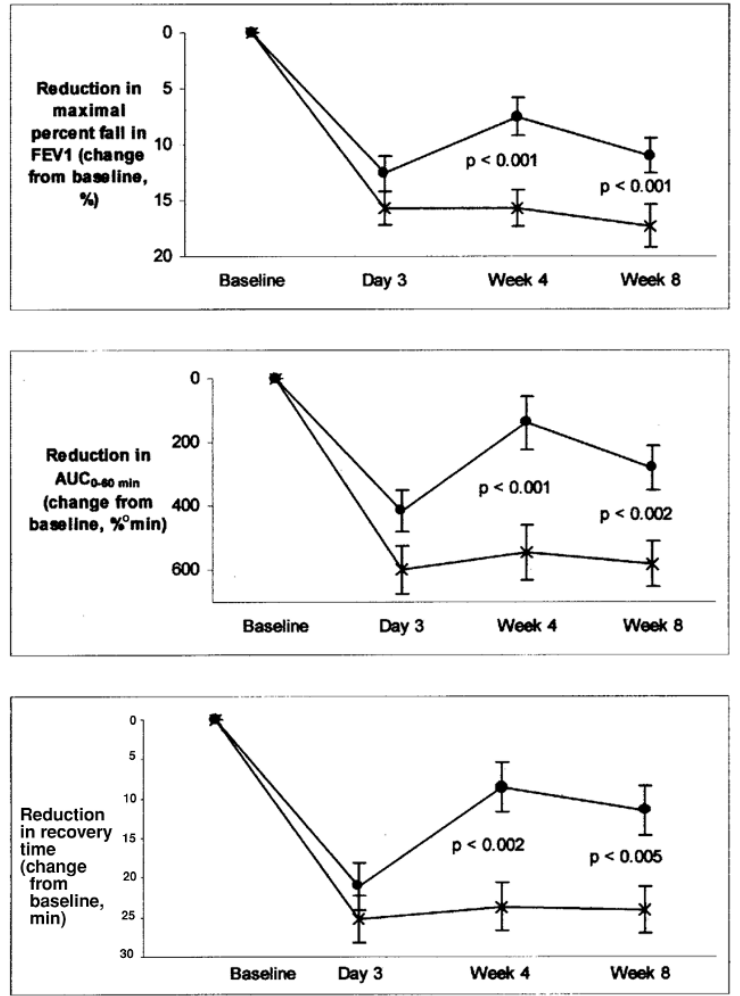

Figure 2 Comparison of montelukast $(X)$ with salmeterol $(\bullet)$ in change from baseline in maximum percentage fall in $\mathrm{FEV}_{1}$ after exercise (top), $\mathrm{AUC}_{0-60 \mathrm{~min}}$ (middle) and time to recovery (bottom). Reproduced with permission from Villaran $\mathrm{C}$ et al. ${ }^{23} \mathrm{AUC}=$ area under the curve; $\mathrm{FEV}_{1}=$ forced expiratory volume in 1 second.

LTRA administration. Another group reproduced these findings by showing similar protection against EIB during the first 3 days of treatment with either montelukast or salmeterol, but again, the protection was lost in the salmeterol group after 4 weeks of treatment. Protection was maintained in the montelukast group through the study's duration of 8 weeks. ${ }^{14}$

A recent investigation comparing the protective effect of montelukast $(10 \mathrm{mg}$ per day for 3 days) and budesonide (400 $\mu \mathrm{g}$ twice daily for 15 days) in 20 patients with EIB showed both treatments to be effective in reducing the percentage of decrease in $\mathrm{FEV}_{1}$ after exercise when compared to placebo. Additionally, budesonide treatment demonstrated a trend toward better

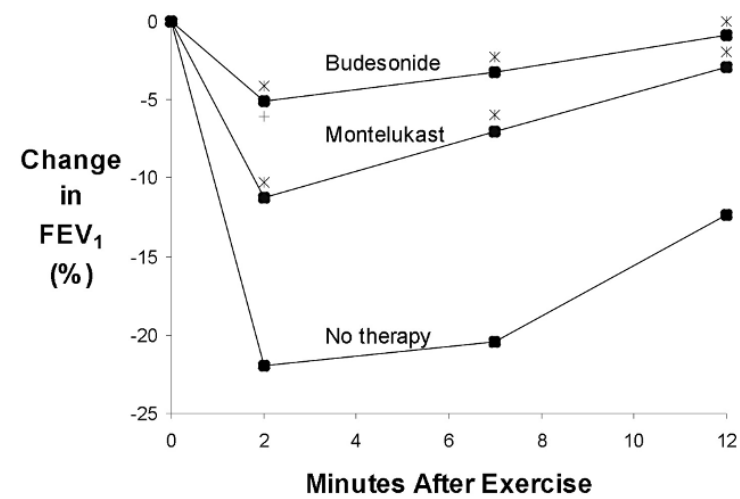

Figure 3 Change in forced expiratory volume in $1 \mathrm{sec}-$ ond $\left(\mathrm{FEV}_{1}\right)$ after exercise at baseline, after budesonide administration, and after montelukast administration in patients with exercise-induced bronchoconstriction. Reproduced with permission from Vidal C et al. ${ }^{8}$

protection than did montelukast treatment at three postexercise time points (2, 7, and 12 minutes), but the difference was significant only at the 2-minute endpoint (Figure 3). Although both treatments were proven to be effective, significant individual variation was evident.

\section{Summary}

As a class, the cysteinyl leukotriene receptor antagonists (LTRAs) are effective in the treatment of exercise-induced bronchoconstriction (EIB). LTRAs can be used as an alternative to lowdose inhaled corticosteroids or can replace inhaled corticosteroids when side effects, poor inhaler administration technique, or noncompliance is suspected. The beneficial effects of LTRAs include increased pulmonary function, decreased symptoms, and decreased use of rescue medication. Montelukast has several advantages over other LTRAs, including formulation, onset of action, duration of action, and a low incidence of adverse effects. Perhaps most important, chronic daily use does not result in the development of tolerance. Montelukast is therefore clinically useful for protection against EIB in children and adults, resulting in increased physical activity and quality of life. 


\section{References}

1. Blake KV. Montelukast: data from clinical trials in the management of asthma. Ann Pharmacother 1999;33:1299-314.

2. National Heart, Lung, and Blood Institute, National Asthma Education Program. Guidelines for the diagnosis and management of asthma. Expert Panel report II. Bethesda (MD):US Department of Health and Human Services; 1997. Pub. No.: 97-4051.

3. Gotshall RW. Exercise-induced bronchoconstriction. Drugs 2002;62:1725-39.

4. Marciniuk DD, Cockcroft DW. Exercise-induced bronchoconstriction: the role of leukotriene modifiers in therapy. Can J Allergy Clin Immun 1998;3:298-303.

5. Salvi SS, Krishna MT, Sampson AP, Holgate ST. The anti-inflammatory effects of leukotrienemodifying drugs and their use in asthma. Chest 2001;119:1533-46.

6. Drazen JM, Israel E, O'Byrne PM. Treatment of asthma with drugs modifying the leukotriene pathway. N Engl J Med 1999;340:197-206.

7. Renzi PM. Antileukotriene agents in asthma: the dart that kills the elephant? CMAJ 1999;160: 217-223.

8. Vidal C, Fernandez-Ovide E, Pineiro J, et al. Comparison of montelukast versus budesonide in the treatment of exercise-induced bronchoconstriction. Ann Allergy Asthma Immunol 2001;86:655-8.

9. American Thoracic Society. Guidelines for methacholine and exercise challenge testing. Am J Respir Crit Care Med 2000;161:309-29.

10. O’Byrne PM. Leukotriene bronchoconstriction induced by allergen and exercise. Am J Respir Crit Care Med 2000;161:S68-72.

11. Tan RA, Spector SL. In: Weisman IM, Zeballos RJ, editors. Clinical exercise testing. Basel: Karger; 2002. p. 205-16.

12. Tan TA, Spector SL. Exercise-induced asthma: diagnosis and management. Ann Allergy Asthma Immunol 2002;89:226-36.

13. Inman MD, O'Byrne PM. The effect of regular inhaled albuterol on exercise-induced bronchoconstriction. Am J Respir Crit Care Med 1996;153:65-9.
14. Edelman JM, Turpin JA, Bronsky EA, et al. Oral montelukast compared with inhaled salmeterol to prevent exercise-induced bronchoconstriction. Ann Intern Med 2000;132:97-104.

15. Jonasson G, Carlsen KH, Hultquis, C. Low-dose budesonide improves exercise-induced bronchospasm in schoolchildren. Pediatr Allergy Immunol 2000;11:120-5.

16. Thio BJ, Slingerland GL, Nagelkerke AF, et al. Effects of single-dose fluticasone on exerciseinduced asthma in asthmatic children: a pilot study. Pediatr Pulmonol 2001;32:115-21.

17. Takahashi N, Ishibashi Y, Murakami Y, et al. Beneficial effect of combination therapy with ozagrel and pranlukast in exercise-induced asthma demonstrated by krypton- $81 \mathrm{~m}$ ventilation scintigraphy - a case report. Ann Acad Med Singapore 2000;29:766-9.

18. Lehnigk B, Rabe KF, Dent G, et al. Effects of a 5-lipoxygenase inhibitor, ABT-761, on exerciseinduced bronchoconstriction and urinary LTE4 in asthmatic patients. Eur Respir J 1998;11: 617-23.

19. Coreno A, Skowronski M, Kotaru C, McFadden ER. Comparative effects of long-acting \{158\}2agonists, leukotriene receptor antagonists, and a 5-lipoxygenase inhibitor on exercise-induced asthma. J Allergy Clin Immunol 2000;106: 500-6.

20. Pearlman DS, Ostrom NK, Bronsky EA, et al. The leukotriene D4-receptor antagonist zafirlukast attenuates exercise-induced bronchoconstriction in children. J Pediatr 1999; 134:273-9.

21. Reiss TF, Hill JB, Harman E, et al. Increased urinary excretion of LTE4 after exercise and attenuation of exercise-induced bronchospasm by montelukast, a cysteinyl leukotriene receptor antagonist. Thorax 1997;52:1030-5.

22. Leff JA, Busse WW, Pearlman D, et al. Montelukast, a leukotriene-receptor antagonist, for the treatment of mild asthma and exerciseinduced bronchoconstriction. N Engl J Med 1998;16;339:147-52.

23. Villaran C, O'Neill SJ, Helbling A, et al. Montelukast versus salmeterol in patients with asthma and exercise-induced bronchoconstriction. Montelukast/Salmeterol Exercise Study Group. J Allergy Clin Immunol 1999;104:547-53. 